\title{
"I Teach Better with the Puppet" - Use of Puppet as a Mediating Tool in Kindergarten Education - an Evaluation
}

\author{
Ronit Remer $^{1, *}$, David Tzuriel ${ }^{2}$ \\ ${ }^{1}$ Pre- school \& Special Education Studies, Levinsky College of Education Tel-Aviv, Israel 6148101 \\ ${ }^{2}$ School of Education, Bar-Ilan University Ramat-Gan, Israel 5290002 \\ *Corresponding author: ronitremer@bezeqint.net
}

Received January 11, 2015; Revised February 26, 2015; Accepted March 05, 2015

\begin{abstract}
A focus of interest among researchers and educators is to find teaching methods adjusted to developmental aspects in early childhood. Teaching that generates significant learning and creates motivation, interest and enjoyment in young children is a real challenge in contemporary education. The effectiveness of using puppets in early childhood has been demonstrated in clinical areas as having the potential to create communication, increase involvement and change attitudes. However, there is limited research literature relating to the use of puppets as a teaching method, and therefore a methodology based on measurement and evaluation is lacking in this field. This article presents partial results of a broader study that examined the influence of an intervention program integrating a puppet as a mediation tool on learning motivation, and enhancing literacy achievements in regular and special kindergarten children. One of the aims of this research was to evaluate, from mediators' perspectives, the use of puppets as a mediation tool for kindergarten children. This evaluation was carried out by means of personal interviews with each of the mediators at the end of the intervention program. From the interviews it became apparent that the mediators considered the puppets to be an effective tool for young children's developmental aspects, by means of which they could relate to cognitive, emotional, and social realms. Mediation using puppets facilitated learning processes, while using puppets, children's cooperation level increased, as did interest, attention span and their involvement in learning interaction was evident. The puppets contributed to the mediators' self-confidence and to their sense of professionalism. During the puppets mediation, the mediators felt that they were teaching in a clear manner, and they felt they were being interesting and: interactive. By using puppets, they succeeded in creating a close personal connection with the children. These findings have an applicable contribution in presenting the effectiveness of the puppet as a mediation tool for use in kindergarten and with special needs children.
\end{abstract}

Keywords: puppets, mediation tool, kindergarten, special education

Cite This Article: Ronit Remer, and David Tzuriel, ""I Teach Better with the Puppet" - Use of Puppet as a Mediating Tool in Kindergarten Education - an Evaluation." American Journal of Educational Research, vol. 3, no. 3 (2015): 356-365. doi: 10.12691/education-3-3-15.

\section{Introduction}

For hundreds of years puppets have been used as an important tool for transmitting knowledge and are located in the fine distinction between entertainment and learning. They have been recognized as an educational tool for their ability to integrate art, communication and persuasion [1].

The strength of puppets is in their ability to move and speak; through these human abilities they elicit identification by people who can see themselves or part of themselves in the puppets. Through puppets, it is possible to communicate with a wide age range, diverse cultures and various language registers. Through puppets, it is possible to influence children, who are considered "hard to reach" in the usual manner[2,3].
The main goals of the broad research on which this article is based were to investigate the effects of mediation with a puppet on: (a) mediators' teaching strategies; (b) children's motivation in learning and; (c) literacy achievements among children in kindergarten(d) to assess the usefulness of the puppet as a mediation tool from the mediators' perspective.

Both qualitative and quantitative assessment tools were used in this research to provide a broad picture of puppets as a mediation tool in early education. Sections of the research presented in this work focus on the fourth goal.

145 children participants from 15 kindergartens located in central Israel (68 special education and 77 normative kindergartens) participated in the broader research. The special education children, who took part in the research, had a major speech deficiency and other learning disabilities and some of them also displayed emotional difficulties. We chose to include a group of children from 
special education kindergartens because of the importance we attribute to this segment of the population in research that examines the effectiveness of a teaching methodology. Furthermore, 18 mediators - students studying education, participated in the research. Each mediator taught an experimental group that received mediation with a puppet, and a control group, which received mediation, but without puppet. For the purpose of this research, 18 identical puppets were constructed.

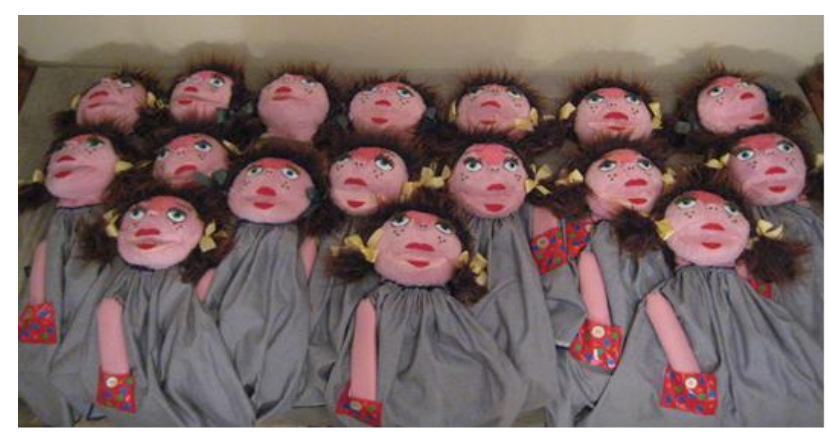

The Research Puppet

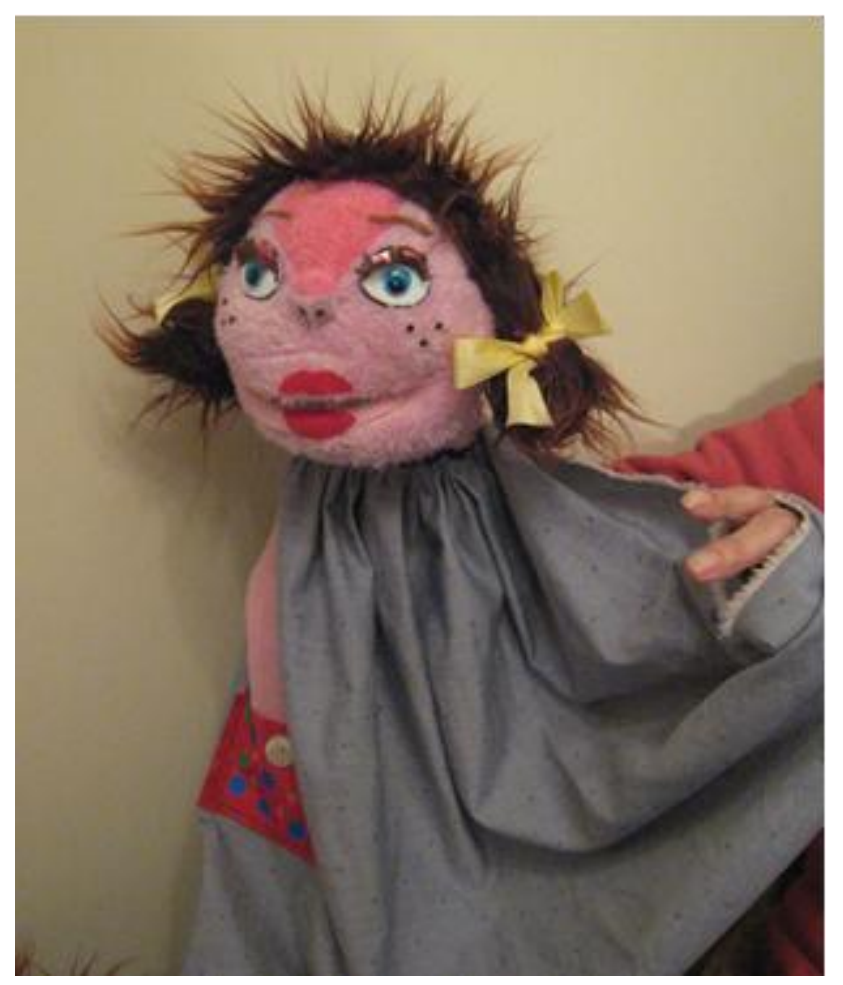

Operation of the Research Puppet

The intervention program was based on research findings and practical experience in the realm of education and therapy, which yielded the value of puppets as an effective tool for young children [4,5]. In addition, the program was based on mediated learning experience theory, which attributes a central place to the implementation of the principles of mediation in adultchild interactions in order to facilitate an effective learning process [6] and on research in the field of learning motivation, from which we surmise that stimulating curiosity and arousing a pupil's interest and involvement are important factors for the development of motivation to learn, and significantly influence cognitive implementation $[7,8,9]$. The effectiveness in using puppets has been examined in the field of literacy because of its importance in the acquisition of reading and writing skills and to the integration of an individual into society [10]. The Observation of Mediation Interaction (OMI)tool was used in this research [11] as well as observations evaluating motivation to learn, which included criteria that, according to research, express motivation and lack of motivation to learn $[12,13]$.

The main findings of the study show that mediating with a puppet increased the use of mediated teaching strategies amongst mediators and increased indices of learning motivation, decreased indices of lack of learning motivation and raised achievements in emergent literacy in comparison with mediation without a puppet. The importance of these findings emerges mainly by exploring the option of turning mediation with a puppet into a methodological way that increases effectiveness and motivation in the teaching process, and helps enhance skills and achievements in groups of young children with different cognitive and behavioral properties.

\section{Puppets as a Mediation Tool in Early Childhood}

Working with puppets is matched to developmental features of young children. During the first few years of their lives, children's thoughts are characterized by animism [14]. They are attracted to dolls, perceive them as living creatures and attribute many different roles to them in playtime. Children recognize dolls as a legitimate and natural part of their world [15].

Researchers emphasize that playing with dolls has a valuable role in the social, emotional and cognitive development of young children. Through a doll, a child creates a process of "projection" - his inner world is projected on to the doll and it is as if it becomes "myself", so that a doll enables a child to express him and serves as an outlet for his emotions [16].

Puppets differ from dolls in their form and in the manner in which a young child plays with them. Dolls are completely sculpted and fixed and their function in game playing is determined by a child by imitating the reality he adjusts to his needs. In contrast, puppets are only partially formed and a child in play activates them, thereby giving them "a life of their own" while still controlling them. While activating puppets, a child can project his emotions onto it [15].

\section{Puppets for Communication and Therapy Needs}

Puppets are a cross cultural medium and reach the hearts of children all around the world [2,3]. Numerous reports exist of wide use of puppets for evaluation, diagnosis, counseling and treatment. Use of puppets for these needs is done in the framework of psychotherapy, family, behavior and clinical therapy [17].

Treatment using puppets combines principles and techniques from various fields: art therapy, play, drama therapy and psychodrama. The approach is known as psycho puppetry [18]. 
Researchers, who have examined the efficiency of using puppets for therapy and communication needs, have emphasized the positive effect puppets have on therapists in assisting children in overcoming their anger, frustrations and fears. Use of puppets has increased the effectiveness of assistance administered to children during periods of illness and hospitalization and in coping with trauma; their effectiveness was particularly pronounced when used to communicate with very young children and increase their self-confidence [4,16,19,20,21].

Researchers emphasize that young children experience difficulties in coping with direct questions with regard to their feelings and emotions, and to encourage their cooperation we must connect to their world which includes stories, dolls and play.

Using puppets helps children express their feelings and thoughts, which would otherwise remain hidden [22, 23]. Through puppets, children can freely and legitimately express their feelings without any guilt or fear. The strength of treatment with puppets lies in its being a powerful projection tool. The child can identify himself in the puppet while at the same time not feel identical to it. In this situation, one's deepest feelings can surface, free from inhibitions [19].

Therapy work with puppets can also be done in a group. The group can serve as a therapist's instrument for identifying problems, identifying and reflecting feelings and providing feedback. The puppet in such a framework can be operated by both the facilitator and individuals in the group [16].

\section{Puppets in Education and Teaching}

The power of puppets as an educational tool lies in its being a type of three- dimensional symbolic art form and being able to move and speak. Because of these characteristics, it serves as a vehicle for transmitting knowledge though a number of senses, thereby providing an opportunity for a wide range for learning abilities. The effectiveness of such learning using a number of senses is the main message in Gardner's "Multiple Intelligences" theory [24].

Use of puppets as a mediation tool in a setting of learning interaction can serve as a tool by which a dialogue can be developed to engage children, explain abstract ideas, demonstrate processes and concepts and, in this way, ease the learning process $[25,26]$. Use of puppets in education as a mediation tool for young children creates a connotation of play so that they enthusiastically participate in any interaction involving puppets [27]. Play is one of the central experiential activities appropriate to the developmental needs and learning process of young children. The framework of play provides ideal conditions for raising the quality of learning and acquisition of knowledge. Learning through play is done easily, without fear or obstacles, and the knowledge acquired is assimilated and not forgotten for a long time [28]. Young children love to pretend and the integration of puppets in educational and social interaction gives them the opportunity to opt for this behavior [29].

Researchers and educators who are aware of the effectiveness of puppets in education and teaching implement intervention programs incorporating puppets in order to impart knowledge and raise children's level of achievement. All these programs have shown a positive effect as a result of the use of puppets on subjects examined. From these findings it is apparent that the knowledge acquired and involvement of children who participated in intervention programs using puppets were higher than those of their counterparts who had participated in intervention programs, but without puppets $[4,30,31,32,33]$.

This study shows that children engage in fruitful dialogue, feel involved in a lesson and explain their answers at length, much more so when puppets are integrated into a lesson. These behaviors are more prominent in children who have less self-confidence or are bashful and usually less likely to join in.

Researchers claim that the most significant factor that contributes to children's high involvement in a learning interaction is due to the fact that a puppet is perceived as a peer, and in that way they are eager to explain to her clearly and in detail their ideas and answers, as opposed to responses and explanations meant for adults, who in any case already know the answer and understand things, even if not explained at length and in detail. Activating a puppet as a character that does not understand the material being taught allows a teacher to ask questions, raise issues and present misconceptions without arousing resistance in children and thereby encourages them to explain and justify their ideas with the purpose of convincing the puppet [32].

Use of a puppet by educators has been found to be effective in expanding the role of traditional teaching, changing teaching patterns, reflective observation of the educational process and professional development [34].

An egalitarian conversation while using the puppet constitutes an opportunity for the educator to minimize control, be surprised and surprise. It is a playful way where the educator can exercise a debate approach, exchange of roles among children and spontaneous flexibility with regard to social and educational issues [35].

One of the areas in which working with puppets is especially effective is that of language skills. Use of puppets makes it possible to plan various activities compatible with the goals of the early childhood curriculum. For example, children can be asked to tell the puppet a story they have just learned, to explain words, expressions and messages she does not understand and to help the puppet match letters to sounds. In this way, children practice literacy skills, and in this manner their own grasp of the concepts and knowledge can be assessed [2].

\section{Methodology}

\subsection{Data Collection}

For the purpose of evaluating the use of puppets as a mediation tool in early education, from the mediator's subjective point of view, a semi-structured interview was conducted with each mediator following the intervention program. The interview was conducted by the researcher. The choice of a semi-structured interview was made because of the wish to enable mediators to authentically express their experiences with minimum direction. During the interview, the mediators were asked to relate freely to 
three topics: (1) The contribution of puppets as a mediating tool in their teaching; (2) The contribution of puppets as a mediating tool in the children's learning; (3) The influence of the experience with puppets as a mediating tool on their educational work.

\section{Participants}

The mediating students $(\mathrm{N}=18)$ who implemented the intervention program in kindergartens studied for their B.A. $(\mathrm{N}=10)$ and M.A. $(\mathrm{N}=8)$ in the Early childhood route in a college in the center of Israel and in a Special Education route in a university in central Israel. Ten of the participating mediators were placed in special education kindergartens and 8 were placed in regular kindergartens. Each mediator taught two groups of children: an experimental group that received mediation with a puppet, and a control group, which received mediation without a puppet.

The children $(\mathrm{N}=145)$ who participated in this research were from 15 kindergartens in central Israel. 68 children came from 10 special education kindergartens ( 55 boys and 13 girls) and 77 children came from 5 regular kindergartens (42 boys and 35 girls).

The children's ages were 5 and 7. The special education children had language disabilities in addition to other learning disabilities; most of them had emotional difficulties. Children with complex disabilities such as autism, intellectual disabilities and $\mathrm{CP}$ and children with severe behavior problems did not participate in the research.

\section{Method of Analysis}

The analysis was made in two stages - In the first stage, two major topics from the interviews were processed: (1) Use of puppets as a mediation tool in early childhood; (2) The main areas in which the puppets' contribution to the mediated interaction was expressed. In the second stage data driven content analysis was conducted for each of the topics which emerged in the first stage. The goal of this stage was to focus the general topics into distinct categories. The analysis was conducted by the researcher who is an expert on the topic of puppet as a mediation tool. The analysis was validated by two specialists in the field of education.

For the first topic seven categories emerged representing different aspects in the mediator's evaluation of the puppet as a mediating tool in early childhood. The categories that emerged were: perceived help given by the puppet, enjoyment in working with the puppet, the children's cooperation with the puppet, the puppet's contribution to learning, using a puppet as a mediation tool in other situations, using a puppet as a mediation tool in the future and the difficulties experienced during mediation with the puppet.

The data showed a quantitative feature for each one of the categories that reflected the extent to which the category found expression in the respondents' answers. Therefore it was decided to measure each category using a 4 point scale from $1-4$, with 1 being the highest and 4 being the lowest.
For the second topic, 10 main areas were found in which the contribution of puppet in interactive mediation was expressed: generate interest, attention and motivation in the children, create an emotional relationship with the children, increase the children's involvement in learning, facilitate presentation of interesting explanations, enable further elaboration on a topic being taught, add humor and create a playful atmosphere, direct communication with the children, help maintain rules of behavior in the group, help verify children's understanding and serve as educational role model.

These areas were graded according to the frequency of their appearance in the personal interviews.

\section{Ethics}

The research was conducted with the approval of the Chief Scientist of the Israeli Ministry of Education. Student-teachers gave their consent to participate in the research. For the purpose of implementing the intervention program, e-mails were sent to education students in the college and in two universities in central Israel, suggesting that they participate in the research, which would be accompanied by their training to work with a puppet as a mediating tool in early childhood. Of the entire body of students who participated in the training session, 18 students were selected, who expressed their wish to participate in the research.

As far as the children's participation in the research, consent was given by kindergarten inspectors, kindergarten teachers and parents for their children's participation in the research.

\section{Findings}

Following are examples of the interview findings for each of the two topics examined.

\subsection{Evaluation of the Use of a Puppet as a Mediation Tool in early Education}

Throughout the seven topics presented below, different aspects of the mediator's evaluation of the puppet as a mediation tool are expressed.

Despite their different experiences, the mediators were in agreement with regard to the puppet's effectiveness as a mediation tool.

\subsubsection{Perceived amount of help given by the puppetin the mediation process}

The mediators perceived the use of a puppet to be very helpful to them in the process of mediation (78\%). None of the mediators stated the puppet were of no help at all.

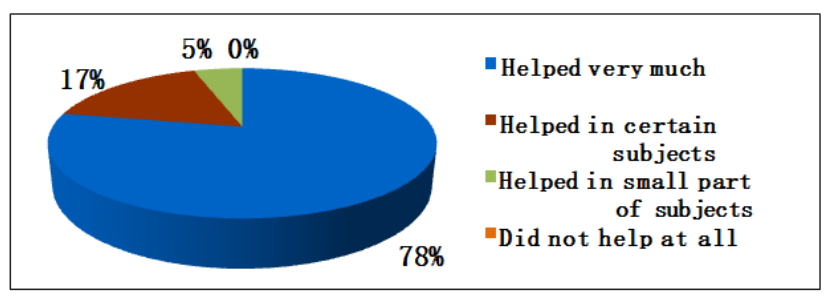

Figure 1. Perceived amount of help given by the puppet 
The mediators stated that through the puppet, they could reflect personally on the process of mediation, and thereby could advance their professional teaching.

D: "The puppet enabled me to engage in a type of reflection, a type of self-examination. Through the puppet, I could allow myself to listen to the children in a different, more focused manner."

$\mathrm{Z}$ related to the fact that the puppet helped her to engage in some personal reflection during the process of mediation and alter the way the mediation was going if necessary.

$\mathrm{Z}:$ "The puppet both represents myself and the children and that causes me to be more conscious of what I say... and mostly more aware of the children ...the puppet can tell me - 'you're confused, you forgot to do... to say... to read'... etc. Without the puppet, I would have to think of another way that was nice and respectful to criticize myself without sounding foolish."

The mediators stated that the puppets helped to raise their self-confidence.

Y: "The puppet gave me confidence since I felt less exposed. The puppet served as a type of cover. I felt that when I am with the puppet, the spotlight is on her and not on me, and if I make a mistake, it's the puppet and not me."

\subsubsection{Level of enjoyment of Mediation in working with the puppet}

Findings indicate that approximately $90 \%$ of the mediators enjoyed working with the puppet for the most part. None of them stated that they did not at all enjoy working with the puppet.

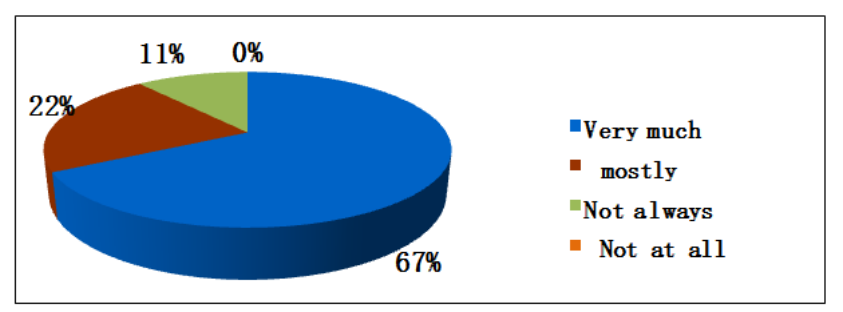

Figure 2. Level of enjoyment of Mediation in working with the puppet

The mediators emphasized that their enjoyment derived from the challenge involved in using puppet.

$\mathrm{N}$ : "As a mediator, it was more interesting teaching the literacy sections using the puppet; it was challenging for me."

A: "I enjoyed working with the puppet. I felt that I was teaching better by using the puppet; I even felt I had more motivation when working with the puppet. It was more interesting for me."

Sometimes, the enjoyment derived from the perception that working with puppet was an innovative way of teaching.

$\mathrm{H}$ : "I enjoyed working with the puppet in the intervention program; it was my first experience working with this age group and in special education."

\subsubsection{Level of children's cooperation with the puppet}

Most mediators (84\%) reported that all the children cooperated with the puppet and regarded them as part of the group. None of the mediators reported any cases of noncooperation by the children.

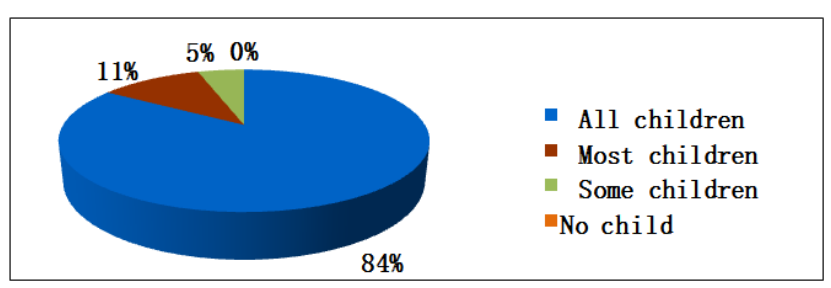

Figure 3. Level of children's cooperation with the puppet

A: "The children from the group that was mediated with the puppet asked me from early in the morning 'when are you going to teach us?' And afterwards while they were tested they showed more participation than the children from the other group."

Even children considered quiet or introverted cooperated with the puppet.

Z: "The puppet helped the quieter children participate. For example, whenever I asked a question, children would raise their hand to answer, except for that quiet little girl. The puppet asked if perhaps that girl knew the answer and I replied, 'Yes, perhaps she does', and then indeed she answered the question, which before she had not."

\subsubsection{Level of the puppet's contribution to learning}

The mediators agreed that the puppet had contributed to the children's learning (72\%). None of the mediators reported that the puppet did not help at all.

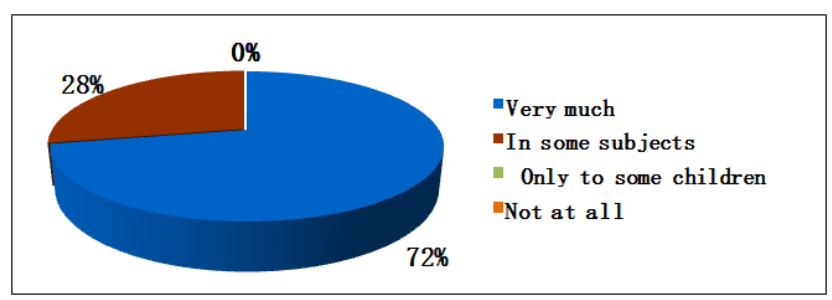

Figure 4. Level of the puppet's contribution to learning

In the mediators' opinion, puppet have visual and verbal characteristics which cause her to become an effective mediation tool affecting a number of senses, thereby serving as a most significant tool in learning.

$\mathrm{H}$ : "The puppet allows me to teach on a few levels. It is a tool that allows contact and in this way it works on the emotional experiential level."

$\mathrm{N}$ and $\mathrm{C}$ noted that the verbal attributes of the puppet encouraged open discussion with the children.

$\mathrm{N}$ : "As far as I'm concerned, the most significant puppet's role is in stimulating conversation with the children."

C: "I noticed that when I worked with the puppet, the group discussion flowed freely. Even children who usually found it hard to participate were taking part and wanted to tell something."

\subsubsection{Level of using the puppet as a mediation tool in other situations}

The interviews revealed that mediators $(\% 94)$ used the puppet as a mediation tool outside the research group as well, in formal and informal education frameworks, and some mediators even made use of the puppet in a family framework. None of the mediators mentioned hardly or not using the puppet at all outside the research group. 


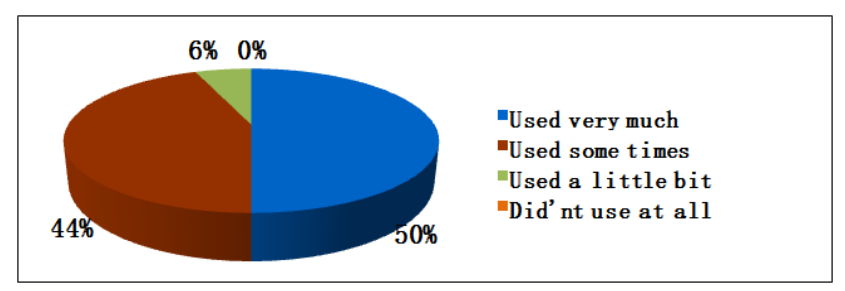

Figure 5. Level of using the puppet as a mediation tool in other situations

Mediators working in special education told of their experiences using the puppet within these frameworks.

M: "I work in special education kindergartens and I make much use of the puppet...I feel that this tool is right for the children, in terms of visual, it draws them and allows me to speak in a few voices. It also allows physical contact with the children... There are many channels to this tool and it increases motivation."

$\mathrm{H}$ related to her work using puppet in a daycare center

$\mathrm{H}$ : "I worked with two year olds and with some of them, it worked very well. I was successful in teaching and explaining things through the puppet."

Use of the puppet in a family framework was described by $\mathrm{T}$.

$\mathrm{T}$ : "I was not having success in toilet training my two year old daughter. The idea of using a puppet popped into my head. I told her that the puppet did not wear a diaper and suggested we pee in the toilet. She agreed to come and also urinated, something that had not happened without the puppet. The process of toilet training took a week."

\subsubsection{Level of using a puppet as a mediation tool in the future}

All the mediators reported that they planned to keep using puppets as a mediation tool in their future professional work. The interviews showed a wide range of reasons behind this intention.

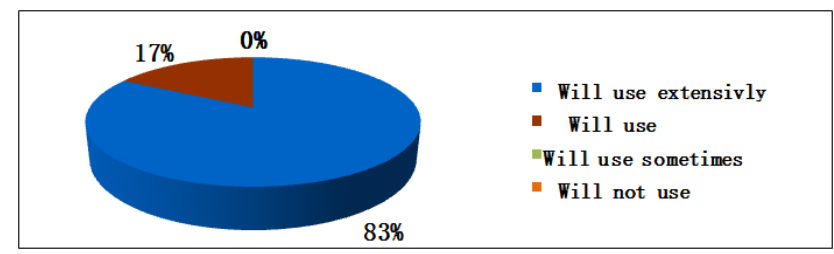

Figure 6. Level of using a puppet as a mediation tool in the future

Using a puppet because of it being a negotiating tool appropriate for specific age groups and special populations -

P: "I believe that I will be using puppets in my future educational work with young children"

R: "Personally, I can relate much more to working with puppets in special education."

Use of a puppet as a mediation tool because of its combination of didactic and emotional aspects.

$\mathrm{S}$ : "I intend to use a puppet to transmit emotional contents that are difficult for a teacher to transmit. A puppet is the sort of mediating tool that makes it easier and more pleasant to transmit the contents and enables the creation of dialogue."

H: "I now feel that the tool is part of me and I will be using it in the future mainly when I encounter educational problems in the children."

\subsubsection{Level of difficulty experienced during mediation} with the puppet

Half of mediators reported that they found it hard to use the puppet at first, but as they gained experience they felt an improvement and the degree of difficulty went down. None of the mediators reported that they found it very difficult to use the puppet.

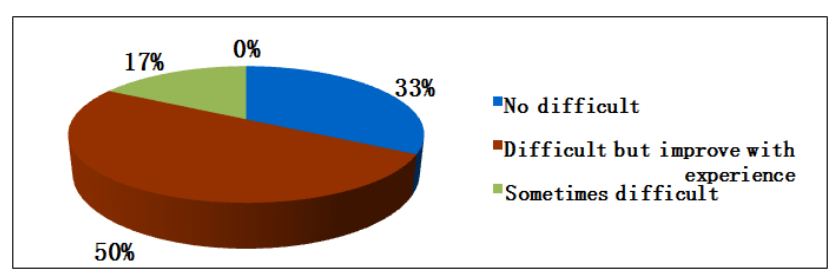

Figure 7. Level of difficulty experienced during mediationwith the puppet

The mediators related that they found it was difficult to figure out how to incorporate puppet into the material being taught.

M: "At first, I found it hard to use puppet...I did not know when exactly to incorporate her into the material being taught and I overdid it... Only when it became clear to me what my role was and that of the puppet's, then the children begin to be more attentive and enjoyed themselves."

Mediators identified a difficulty arising from the necessity to be both themselves and someone else at the same time.

S: "Sometimes it was hard to split my attention and I found myself speaking as myself while activating the puppet and vice versa...There are three factors which must be addressed in working the puppet: activating her, focusing on the content and relating to the children. All of these were hard for me but eventually with practice, I was more successful."

\subsubsection{Main areas in which the contribution of the puppet is expressed in mediation interaction}

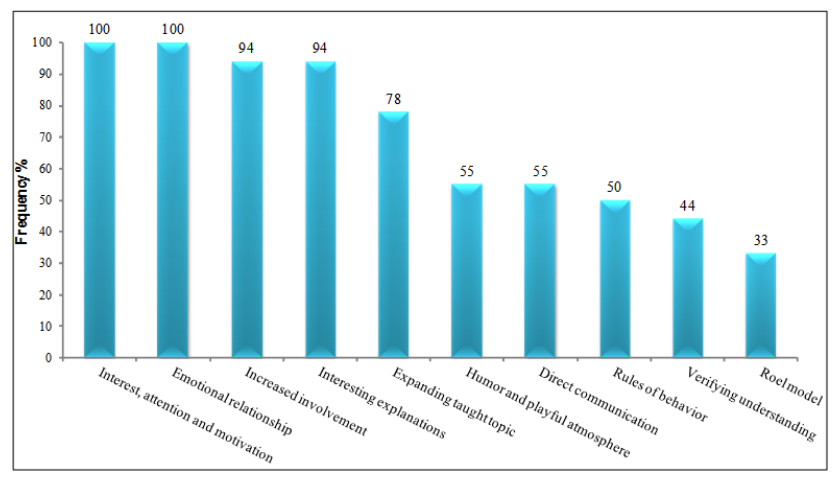

Figure 8. Main areas in which the contribution of the puppet is expressed in mediation interaction

In the opinion of the mediators, using the puppet significantly contributed to advancing the mediation process. Figure 8 shows 10 areas in which the contribution was expressed according to the frequency of their occurrence during the interviews.

Figure 8 reveals that the most frequently mentioned contribution of the puppet is in generating interest, attention and motivation in the children (100\%) and in creating an emotional connection with the children 
(100\%). The least frequently mentioned contribution was it being an educational model worth emulating (33\%).

1. The Puppet helped to generate interest, attention and motivationin the children - all mediators emphasized the presence of the puppet in situations of mediation as being interesting. From their description, it was apparent that interest, attention and motivation of children are intertwined. The effect of the puppet on one of the factors, for the most part interest, instantly raised the others - attention and motivation.

$S$ described the connection between the interest generated by the puppet and the focus on learning created as a result.

S: "I believe the group that had the puppet showed more interest...motivation was higher and learning was better, because they were focused on us - on the studentteacher and on the puppet and it fascinated them to the learning. I see a connection. They waited eagerly to hear her words. If the puppet was about to speak or come out of my bag, they waited expectantly and quietly. The listened to her and her answers and there was a lot of attention paid to the puppet."

$\mathrm{H}$ believed that interest was due to the fact that the puppet broke the routine of learning to which children are accustomed in kindergarten.

$\mathrm{H}$ : "The puppet breaks the learning routine to which the children are used in the kindergarten and so she adds interest. Instead of my asking the children questions, the puppet asks questions and this makes the lesson less boring, because when I ask a lot of questions, it might be boring."

The interest generated by the presence of the puppet in educational situations increased children's attention span, mostly those in special education.

$\mathrm{H}$ : "The puppet was a highly significant focal point of interest for the children. She was desirable at almost any given moment. And these are children who normally find it very difficult to concentrate and here I am sitting with them for 40 minutes."

2. The puppet helped to create emotional relationship with the children - Together with increasing their interest, attention and motivation in learning, the mediators noted the fact that children felt freer to share their personal experiences with the puppet.

$\mathrm{Y}:$ "The puppet is perceived as a kind of child, so the children felt free to participate and speak..."

M: "Whenever I taught using the puppet, the discussion involved an emotional element connected to the children's world."

$\mathrm{N}$ was surprised to see the openness that characterized the dialogue between one of the children and the puppet, mostly due to the fact that the child was usually introverted.

$\mathrm{N}$ : "When I taught the story about the turtle and scorpion using the puppet, I asked the children where the turtle lived and they answered ...then one of the children said he lived in two houses, one at his mother's and one at his father's. He said that sometimes he was with his father and sometimes with his mother. Afterwards, the kindergarten teacher revealed that the child had never mentioned his parents' divorce which had taken place not so long before."

3. The puppet helped increase the children's involvement in learning - according to the mediators' reports children's involvement increased when they took an active role in the mediation interaction.

$\mathrm{H}$ : "The puppet contributed to the children's participation in learning situations; she led to their participation. In the presence of the puppet, the children were engaged and asked questions."

One of the ways to up children's level of participation was by the puppet addressing them directly and requesting their help.

S: "The puppet said: I'm not sure I understood" and repeated the main idea of the text. I then asked the children if the puppet had understood it correctly. The fact that the children can answer yes or no empowers them. All the children volunteered answers as to whether the puppet was right or wrong."

4. The puppet facilitated presentation of interesting explanations - the mediators noted that one of the outstanding ways they used the puppet to stimulate the children was by making her seem confused.

$\mathrm{R}$ : "The puppet got confused and the mix-up makes the lesson more interesting. You can repeat the explanation a number of times until the puppet understands it, and in this manner it is also internalized by the children."

Another way in which mediators explained the material being taught was through the puppet's questions.

Y: "The puppet really helped me to explain difficult words. I had to constantly explain things to her and she also asked the children questions and some of them also helped to explain things."

5. The Puppet enable further elaboration on a topic being taught -the mediators reported that personal examples and experiences brought to the discussion using puppet encouraged the children to add their examples and experiences thus broadening the discussion.

D: "I felt that the puppet especially helped me when it provided examples from her world and her experiences connected to the text. This in turn caused the children to bring up their own examples and experiences."

$\mathrm{N}$ related to the way in which she went beyond the material being taught using the emotional realm, which a child raised during the learning interaction with the puppet.

$\mathrm{N}$ : "In one encounter, a child said that like the girl in the song we learnt, he also wanted his mother to remain at home, because his dog had died and he was sad. The puppet asked him questions about the dog and about his mother. I felt that he was talking more to the puppet than to me... When he managed the conversation through the puppet, I noticed the group was more focused."

6. The Puppet added humor and created a playful atmosphere - mediators reported that during mediation using the puppet, the atmosphere in the group was cheerful and the children laughed a lot and there was a sense of playing an enjoyable game.

P: "... The puppet helped get the group to laugh, in other words, to experience laughter, which wouldn't have happened otherwise, meaning in the group without the puppet."

The value of humor in the learning interaction is expressed in B's words:

B: "I tried to use the puppet to make the children laugh in order to direct their attention and I saw that it indeed helped."

7. The puppet allowed for direct communication with the children -mediators reported that the fact the 
puppet portrayed the persona of a little girl allowed them to speak through her and use childish language, and in this manner created a form of direct "eye to eye" communication.

$\mathrm{H}:$ "It is important that the puppet is a character of a sweet little girl who goes to kindergarten. This creates common grounds with the children and enables closeness."

$\mathrm{C}$ and $\mathrm{H}$ related to the characteristics of direct communication, which in their opinion, cannot be attained by a mediator.

C: "I think a puppet brings with her something the kindergarten teacher cannot bring to the learning situation. She creates a sort of intimacy that the kindergarten teacher, as an adult, can never bring with her."

$\mathrm{H}:$ "The puppet enables learning at eyelevel with the children. The puppet can speak in their language. She comes from the emotional and social world of the child. I can't do that because it's uncomfortable for me, I'm their teacher."

8. The puppet helped maintain rules of behavior in the group - mediators reported that even though the puppet did not directly comment on the children's misbehavior in the group, they did play a role in watching over them. This role was carried out in two ways: firstly in a preventative manner by creating an interesting learning atmosphere for the children, raising the attention level and decreasing the disruptions, and secondly in an indirect manner, when the puppet told about her proper behavior in her kindergarten.

$\mathrm{N}$ : "The puppet helped me to divert the children from disruptions and focus them again. If the child begins to lose attention, I would say: 'Wait a minute, the puppet has a question to ask', or the puppet would address a child and ask him what he had to say about one of the subjects we learned so that he regained his focus."

$\mathrm{S}$ : "The puppet helped to maintain good behavior by explaining the proper way to behave in her kindergarten."

Although the puppet helped maintain appropriate behavior the mediators emphasized they did not use it directly for disciplining the group.

C: "I didn't use the puppet for disciplining the group. When I did need to discipline, I used my voice, and the puppet didn't take part, but rather was like one of the children in the room."

9. The puppet helped verify the children's understanding - mediators reported that through the dialogue that took place between the puppet and the children, it was possible to check the degree to which the children had understood the text being taught.

$\mathrm{S}$ : "With the help of the puppet, I could check the children's knowledge and understanding by asking them to explain words or ideas to the puppet"

In a similar manner, B allowed the puppet to ask the questions,

B: "The puppet didn't understand and asked some questions and the children had to answer...the puppet gave an incorrect answer and the children needed to correct her, and that way I could assess how much they understood."

10. The puppet served as educational role model mediators noted that by identifying with the puppet, the children imitated her behavior. The way the puppet acted in the learning interaction encouraged similar behavior on the children.

$\mathrm{S}$ : "In my opinion, in the group where I worked using the puppet, learning was better because beyond the fact that the puppet stirred up interest in learning, she also became a role model for the children, by asking questions and answering with explanations."

Because of the children's identification with the puppet, there was great importance to learning difficulties that could be expressed via the puppet. Expressing difficulties through the puppet gave legitimacy to the children's difficulties and let them express their difficulties without feeling like failures.

M: "The puppet used to get mixed up and that gave legitimization to the children that they are allowed to be confused."

\section{Conclusion}

The aim of this article was to present the benefit of the use of puppets as a mediating tool for children in the regular and the special education kindergarten. It became apparent from the interviews with the mediators that a puppet is an effective mediating tool both for children and mediators.

For the children the main contribution of the puppet was that she allowed for creating interest and attention in children, developing a dialogue with them and thereby encouraging their participation. This involvement is particularly emphasized in children who are introverted and quiet, who had not participated previously. Through a puppet's "personal experiences", discussions ensued on topics that are far from the "here and now", thus enriching the learning.

The integration of the puppet enabled mediators to combine playful dialogue and humor, which increased enjoyment. The childish language that characterizes the use of puppet, allowed for conversations with the children "in their language", thus gaining their trust. Difficulties and failures that were expressed by the puppet gave legitimization to the children not to be afraid of making mistakes. Because of the children's identification with the puppet, they tried to imitate her and in this way, the mediator promoted adaptive behavior.

The puppet's main contribution to the mediators was that working with her was perceived to be an innovative teaching method that challenged them. When they used the puppet, they felt they were interesting, attractive, mediating effectively, and successful in forming a personal connection with the children. These feelings enhanced their self-confidence and raised their sense of professional competence in teaching.

These findings are compatible with research reports and professional literature that emphasize the advantages of puppets as a mediation tool and describe the satisfaction and sense of challenge accompanying its use [5,25,26]. According to the Mediated Learning Experience, the emotional realm greatly affects learning $[9,11]$. Hence, the integration of a puppet, which according to mediators had a positive effect on the children's emotions, could exert a positive influence on motivation and achievements as well.

Furthermore, according to this theory, children with special needs find it difficult to respond to regular 
mediation, but adjusted mediation could affect a powerful and essential cognitive change [36].

Because of the power of the puppet as a mediation tool, as emerged from the interviews, she can serve to create a cognitive change in children that have learning difficulties $[2,3]$.

Beside the theoretical aspects, this research has an applicable contribution for educators as an alternative way toempower their mediation and to strengthen their sense of competence and inclusion in teaching. The integration of a puppet into the kindergarten teacher's work can help to connect with children, encourage their verbal expression, decrease their feelings of stress and anxiety and create a sense of pleasure and playfulness. Those aspects are highly significant especially when working with children that have cognitive and linguistic difficulties. Hence, it is recommended to integrate a puppet into learning, educational and social interaction situations in kindergartens in general and in special education in particular.

Since a puppet is a mediating tool that increases interest and motivation in learning, there are important implications for integrating it in programs for cognitive and linguistic advancement for children who have experienced learning failures, adjustment difficulties and emotional disorders.

Mediating with a puppet involves a variety of significant linguistic interactions and therefore, it is recommended to integrate a puppet in programs for promoting language and encouraging conversation among children with language difficulties.

In order that for work with a puppet as a mediation tool to become part of the early childhood educator's "toolbox", it is important for early childhood teachers in training to learn this work method, so as to know the technical skills of operating a puppet as well as the contexts into which a puppet could be integrated in teaching and in education.

\section{References}

[1] Crepeau, M. I., \& Richards, I. M. (2003). A Show of Hands: Using puppets with Young Children. St. Paul: Redleaf Press. 2003.

[2] Peck, S., M. Puppet Power: "A Discussion of how puppetry supports and enhances reading instruction". In M. Bernier \& J. O'Hare (Eds.), Puppetry in Education and Therapy: Unlocking Doors to the Mind and Heart. Bloomington Indiana: Author House. 2005, 73-81.

[3] Smith, L. "Social competency skills through puppetry". In M Bernier \& J. O'Hare (Eds.), Puppetry in Education and Therapy: Unlocking Doors to the Mind and Heart. Bloomington, Indiana: Author House., 2005, 73-81.

[4] Epstein, I., Stevens, B., McKeever, P., Baruchel, S., \& Jones, H. "Using puppetry to elicit children's talk for research". Nursing Inquiry, 15 (1), 49-56. February, 2008.

[5] Keogh, B., \& Naylor, S. "Puppets count", Mathematics Teaching, 213, 32-34, March, 2009.

[6] Feuerstein, R., Rand, Y., \& Hoffman, M. B. The Dynamic Assessment of Relate Performers: The Learning Potential Assessment Device, Theory Instruments and Techniques. Baltimore: University Park Press. 1979.

[7] Lepper, M. R., Corpus, J. H., \&Iyengar, S. "Intrinsic and extrinsic motivational orientations in the classroom: Age differences and academic correlates". Journal of Education Psychology, 97(2), 184-196. May, 2005.

[8] Tzuriel, D. "Development of motivational and cognitiveinformational orientation from third to ninth grades". Journal of Developmental Applied Psychology, 10, 107-121. Jan-Mar, 1989.
[9] Tzuriel, D. "Cognitive modifiability, mediated learning experience and effective-motivational processes: A transactional approach", In R. Feuerstein, P. S. Klein, \& A. J. Tannenbaum (Eds.), Mediated Learning Experience (M L E): Theoretical Psychosocial and Learning Implications. London: Freund Publication House. 1991, 95-120.

[10] UNESCO Institute for Statistic. Literacy skills for the world of tomorrow: Further results from PISA 2000. Paris: OECD. 2003.

[11] Klein, P. S. Early intervention: Cross cultural experiences with a Mediational Approach. New York: Garland. 1996.

[12] Assor, A., Roth, G., \& Deci, E. L. "The emotional costs of parents' conditional regard: A self-determination theory analysis", Journal of Personality, 72, 47-89. February, 2004.

[13] Katz, I., \&Assor, A. "When choice motivates and when it does not." Educational Psychology Review, 19, 429-442. August, 2007.

[14] Piaget, J. The Child's Conception of the World. Rowman\& Littlefield. 2007.

[15] Yoeli, N. Theater Puppets and children-from Play to Art. Tel Aviv: National "Culture Basket" (Hebrew). 2008.

[16] Bernier, M. Introduction to puppetry in therapy. In M. Bernier \& J. O'Hare (Eds.), Puppetry in Education and Therapy: Unlocking Doors to the Mind and Heart. Bloomington Indiana: Author House. 2005, 109-115.

[17] Butler, S., Guterman, J. T., \& Rudes, J. (2009). Using puppets with children in narrative therapy to externalize the problem. Journal of Mental Health Counseling, 31 (3), 225-233.

[18] Bernier, M. (1990). Psycho puppetry. Unpublished manuscript, Eastern Virginia Medical School, Norfolk, VA.

[19] Aronoff, M. "Introduction: Puppetry as a Therapeutic Medium". In M. Bernier \& J. O'Hare (Eds.), Puppetry in Education and Therapy: Unlocking Doors to the Mind and Heart. Bloomington Indiana: Author House, 2005, 117-124.

[20] Chiles, D. "The therapeutic use of puppetry in a health care setting". National Festival Workshop Manual: 2001 A Puppet Odyssey .Puppet of America. 2001.

[21] Pélicand, J., Gagnayre, R., Sandrin-Berthon, B., \&Aujoulat, I. "A therapeutic education programme for diabetic children: recreational, creative methods and use of puppets". Journal of Patient Education Counseling, 60 (2), 152-163. February, 2006.

[22] Ablow, J.C., \&Measelle, J. R. (1993). The Berkeley Puppet Interview (BPI): Interviewing and Coding system Manual. Unpublished manu.

[23] Cooper-Keisari, S. (2009). What helps me when things are difficult. Hed Hagan, 4 52-61

[24] Linn, S. "Foreword". In M. Bernier \& J. O’Hare (Eds.), Puppetry in Education and Therapy: Unlocking Doors to the Mind and Heart. Bloomington Indiana: Author House. 2005.

[25] Lowe, J., \& Matthew, K. "Puppets and prose-using puppets and children's literature in the science classroom", Science and Children, 37, (8), 41-45. May, 2000.

[26] Salmon, M., \&Sainato, D. "Beyond Pinocchio: puppets as teaching tools in inclusive early childhood classrooms". Young Experience Children, 8 (3), 12-19. March, 2005.

[27] Leyser, Y, \& Wood, J. "An evaluation of puppet intervention in a second grade classroom", Education, 100 (3), 292-296. March, 1980.

[28] Bennett, N., Wood, L., \& Rogers, S. Teaching through play: Teacher's Thinking and Classroom Practice. Buckingham, UK: Open University Press. 1997.

[29] Synovitz, L. "Using puppetry in a coordinated school health program", Journal of School of Health, 69 (4), 145-147. May, 1999.

[30] To, Q. G., Le H. K., Dao, T. T., Magnussen, C. G., \& Le, Q. T.. "Effectiveness of a puppet show on iodine knowledge, attitudes and behavior of elementary students and the indirect effects on their parents and households in Ho Chi Minh City: A pilot study". Public Health, 124 (9), 538-541. September, 2010.

[31] Schmidt, K. C. "Comparison of three teaching methods on 4through 7-year-old children's understanding of the lungs in relation to a peak flow meter in the management of asthma: A pilot study". Journal of Asthma, 39 (7), 641-648. October, 2002.

[32] Simon, S., Naylor, S., Keogh, B., Maloney, J., \& Downing, B. "Puppets promoting engagement and talk in science". International Journal of Science Education, 30 (9), 1229-1248. July, 2008.

[33] Zaccone-Tzannetakis, P. R. "We can protect ourselves: A rhyming puppet show about HIV prevention". The Journal of School Healthhttp://www.quickim.co.il/it-seems-today-that-kilptam-not- 
orange-peel-it-easily-and-without-getting-dirty/, 65 (4), 152-153. April, 1995.

[34] Keogh, B., Naylor, S., Maloney, J., \& Simon, S. "Puppets and engagement in science: a case study". Nordina, 4 (2), 142-150. May, 2008.

[35] Yoeli, N. (2003). I, you and the puppet. In: Klein, P.S. and Givon, D. (Eds). Windows to the World (pp. 177-200). Tel Aviv: Ramot Publications Tel Aviv University
[36] Feuerstein, R. \& Feuerstein, S. "Mediated learning experience: A theoretical review". I n R. Feuerstein, P. S. Klein \& A. Tannenbaum (Eds.).Mediated Learning Experience (MLE): Theoretical, Psychosocial and Learning Implication London: Freund Publishing House. 1991, 10-57. 